Cita bibliográfica: Pereiro, X. y Sacramento, O. (2020). Informação e comunicação nos postos de turismo do Douro. Investigaciones Turísticas (20), pp. 239-261. https://doi.org/10.14198/INTURI2020.20.11

\title{
Informação e comunicação nos postos de turismo do Douro
}

\author{
Information and communication in the tourist offices of Douro, Portugal \\ Información y comunicación en las oficinas de turismo del Douro
}

\begin{abstract}
Xerardo Pereiro iD, Universidade de Trás-os-Montes e Alto Douro, Centro de Estudos Transdisciplinares para o Desenvolvimento, Portugal xperez@utad.pt
\end{abstract}

Octávio Sacramento iD, Universidade de Trás-os-Montes e Alto Douro, Centro de Estudos Transdisciplinares para o Desenvolvimento, Portugal

octavsac@utad.pt

\section{RESUMO}

Os postos de turismo são espaços de hospitalidade, de comunicação com os visitantes e de (re)construção de imagens e experiências do destino, podendo mesmo estimular profundas ligações emocionais com o território visitado. Neste texto analisamos o seu papel de mediação comunicacional entre os visitantes e os destinos a partir de um estudo de caso na região do Douro, no Norte de Portugal. Procuramos, assim, compreender os procedimentos de informação e comunicação turística realizados através dos postos municipais de turismo. De forma complementar, é nosso intuito perceber o processo de transformação de muitos destes postos em lojas interativas de turismo, o que implicou mudanças significativas nos processos e práticas de comunicação com os turistas. Os elementos que sustentam a análise foram proporcionados por um trabalho de terreno de natureza quali-quantitiva e multimetódica, embora a abordagem qualitativa tenha assumido maior destaque. Em concreto, a pesquisa empírica foi realizada através da observação participante, de entrevistas semidirigidas, da netnografia e da pesquisa documental e estatística. Os dados apurados evidenciam a existência de constrangimentos estruturais em muitos dos postos de turismo e, por outro lado, mostram-nos a importância do fator humano nos processos de comunicação turística, o que não deixa de suscitar uma reflexão acerca das valências que estes postos deverão assumir no quadro de uma sociedade digital, atulhada em (des)informação.

Palavras-chave: comunicação turística; postos de turismo; Douro (Portugal). 


\section{ABSTRACT}

Tourist offices are welcoming spaces providing services that include the communication with visitors, the (re)construction of images and experiences of the destination and they may even stimulate deep emotional connections with the territory visited. In this paper we analyze their role as communication mediators between visitors and destinations, based on a case study in the Douro region, northern Portugal. The main objective of the study is to gain an understanding of the procedures of tourism information and communication carried out through the municipal tourism posts. A further aim is to analyze the transformation of many of these spaces into interactive tourist offices, implying significant changes in the processes and practices of communication with tourists. The analysis is underpinned by qualitative and multimethod fieldwork, although the qualitative approach is prominent. Specifically, empirical research has been carried out through participant observation, semi-structured interviews, netnography and documentary and statistical research. The data collected reveals the existence of structural constraints in many of the tourist offices and, on the other hand, highlights the importance of the human factor in the processes of tourism communication, which does not fail to give rise to a reflection about the roles and functions that these offices should assume in the framework of a digital society, replete with (un)information.

Keywords: tourism communication; tourist offices; Douro (Portugal)

\section{RESUMEN}

Las oficinas de turismo son espacios de hospitalidad, de comunicación con los visitantes y de reconstrucción de imágenes y experiencias del destino, pudiendo mismo estimular profundos vínculos emocionales con el territorio visitado. En este texto analizamos su papel de mediación comunicacional entre visitantes y destinos a partir de un estudio de caso en la región del Douro, en el Norte de Portugal. De esta manera, procuramos comprender los procesos de información y comunicación turística desarrollados por medio de las oficinas municipales de turismo. De forma complementar, nuestro objetivo es interpretar el proceso de transformación de muchas de estas oficinas de turismo en lojas interativas de turismo, lo que ha implicado cambios significativos en los procesos y prácticas de comunicación con los turistas. Los elementos que sustentan el análisis han sido proporcionados por un trabajo de campo de naturaleza cuali-cuantitativa y multimetódica, aunque la perspectiva cualitativa haya sido más destacada. En concreto, la investigación empírica ha sido desarrollada a través de observación participante, de entrevistas semidirigidas, de netnografía y de investigación documental y estadística. Los datos muestran la existencia de problemas estructurales en muchas de las oficinas de turismo y, por otro lado, la importancia del factor humano en los procesos de comunicación turística, lo que no deja de suscitar una reflexión sobre la importancia que estas oficinas de turismo deberían de asumir en el marco de una sociedad digital, llena de (des)información.

Palabras clave: comunicación turística; oficinas de turismo; Douro (Portugal). 


\section{INTRODUÇÃO}

O turismo mobiliza um extenso volume de dados, pelo que é pertinente considerar que se trata de "an information-intensive industry" (Benckendorff, Xiang e Sheldon, 2019, p. 2). A informação e a sua difusão são particularmente relevantes nos processos de mediação entre a oferta e a procura turística (Cabo Nadal, 2002; Alén et al., 2009; Brito, 2013). É neste âmbito que centramos o presente texto, procurando analisar o turismo enquanto configuração de fluxos informacionais e tendo como referência empírica um estudo de caso sobre os postos de turismo na região do Douro (NUT-III), no Norte de Portugal. Orientamos a análise de modo a compreender as disposições, práticas, imagens e mensagens a partir das quais os postos de turismo procuram assegurar a mediação comunicacional entre visitantes e destinos turísticos. Simultaneamente, procuramos perceber as mudanças nos modos de informação e interação com os turistas que têm vindo a ocorrer na última década, em virtude da crescente proeminência da comunicação turística assente em formatos audiovisuais, digitais, multissensoriais e interativos que as novas tecnologias de informação e comunicação (TIC) têm proporcionado (Buhalis e O'Connor, 2005; Jiménez, Allés e Franco, 2018). À escala regional, esta tendência global de crescente digitalização da atividade turística - "e-tourism" (Buhalis, Leung e Law, 2011) - tem-se manifestado, desde logo, na conversão de muitos dos postos de turismo do Norte de Portugal em lojas interativas de turismo (LIT), que funcionam em rede e tornam possível a comunicação integrada, segundo um sistema que permite fornecer informação, partilhar conteúdos com a rede de lojas, concretizar ações promocionais e apoiar os visitantes na planificação e/ou concretização das suas visitas.

Este texto enquadra-se no âmbito do projeto Dourotur ${ }^{1}$, que está a ser desenvolvido desde abril de 2016 com o objetivo de estudar holisticamente a oferta, a procura, a mediação e o marketing digital do turismo no Douro. Relativamente aos postos de turismo, a recolha de dados assentou numa pesquisa de terreno multimetódica, mas tendo sempre como base a observação participante, segundo a modalidade de cliente mistério, realizada por 8 investigadores de várias nacionalidades nos 23 postos da região do Douro. 0 trabalho foi orientado por um guião de observação constituído por três grupos de itens: a) informação básica; b) outras informações; c) avaliação do posto. ${ }^{2}$ Este guião foi construído com base noutros modelos e foi adaptado à realidade dos postos de turismo do Douro. A primeira fonte de inspiração

1. I\& DOUROTUR - Tourism and technological innovation in the Douro, n.o de operação NORTE-01-0145FEDER-000014, cofinanciado pelo Fundo Europeu de Desenvolvimento Regional (FEDER) através do programa NORTE 2020 (Programa Operacional Regional do Norte 2014/2020), investigador responsável: Prof. Dr. Xerardo Pereiro (UTAD- CETRAD) - xperez@utad.pt. Este projeto é desenvolvido no CETRAD, é um centro de investigação multidisciplinar da UTAD, avaliado internacionalmente pela Fundação para a Ciência e a Tecnologia (FCT) de Portugal, com uma linha de investigação sobre Turismo e Desenvolvimento, financiado por fundos nacionais através da FCT, no âmbito do projeto UIDB/04011/2020. Além do mais, no caso de Xerardo Pereiro, o texto foi escrito no âmbito de uma bolsa de licença sabática no Departamento de Geografia da Universidade de Santiago de Compostela, baixo a orientação do Prof. Dr. Rubén Lois, financiada pela FCT, com o código SFRH/ BSAB/143053/2018. Ver informações detalhadas do projeto em http://dourotur.utad.pt/

2. Mais em específico, o guião contemplou os seguintes aspetos: qualidade do material impresso em geral; guias e mapas do município; guias da região do Douro; material extra; agenda cultural; informação sobre o tempo de viagem até aos atrativos turísticos; material sobre flora e fauna; acessibilidade; sinalética do posto; horário 
foi o modelo de análise que a Organização Mundial de Turismo (OMT) aplica aos centros de informação turística (OMT, 1999, p. 81)3. Outras fontes foram alguns inquéritos aplicados em Espanha: a) o inquérito para a valoração do serviço de informação turística de Gijón; b) o inquérito de opinião dos visitantes do posto de turismo de Salamanca; c) o inquérito sobre qualidade e satisfação do visitante de Cantábria; d) o inquérito de satisfação do visitante do posto de turismo da Comarca de la Sidra (Astúrias); e) o inquérito de opinião dos visitantes do posto de turismo de Santiago de Compostela.

Durante o trabalho de campo, para além da observação participante nos postos de turismo realizada desde abril de 2017 até maio de 2019, pedimos através de correio eletrónico dados quanti-qualitativos sobre os visitantes. Recebemos resposta de 16 dos 19 municípios da região, com dados do ano 2016 e anteriores. Estes dados já foram analisados detalhadamente noutro texto (Pereiro e Sousa, 2021). Agora são aqui brevemente considerados e articulados com elementos provenientes de outros procedimentos metodológicos, o que nos permite cruzar olhares entre o qualitativo e o quantitativo para melhor compreender o papel da comunicação turística nestes postos de turismo. Também realizámos uma análise etnográfica da informação turística nas webs dos municípios dos quais dependem os postos de turismo, sendo que esta "netnografia" (Kozinets, 2010) permitiu aceder a representações institucionais dos destinos e a modos de comunicação com os potenciais visitantes (Mota e Losada, 2017).

A estrutura do texto integra, logo após a introdução, uma breve reflexão teórica sobre a importância da informação e da comunicação turística nos postos de turismo. Segue-se a apresentação do nosso caso de estudo no Douro para, logo depois, procedermos à análise das assimetrias e dos constrangimentos presentes na organização territorial e na gestão dos postos de turismo da região. Mais adiante, focamos a nossa atenção nos processos e práticas de acolhimento, hospitalidade e comunicação nestes postos. Finalmente, encerramos com algumas notas reflexivas tendo em conta as principais perspetivas delineadas ao longo do texto e considerando, simultaneamente, os exigentes desafios relacionados com a construção de uma cultura de acolhimento e de hospitalidade turística.

\section{RECEBER E INFORMAR}

O turismo é um construtor de relatos que tem efeitos nos imaginários sociais, pelo que as imagens turísticas assumem um papel político na definição de identidades e territórios, algo implícito na publicidade e noutros meios de comunicação turística. Estas imagens podem ser estudadas como objeto ou conteúdo de um discurso (imagem projetada ou de promoção), como agentes mediadores dos fluxos turísticos (imagem induzida) e como práticas sociais dos turistas (imagem consumida, percebida, recriada, recordada). Em conjunto constroem a

de funcionamento; informação exterior; informação turística partilhada com outros municípios; perfil dos informadores; espaço de exposição; domínio de línguas dos técnicos que atendem os turistas.

3. Trata-se de um modelo que permite avaliar a acessibilidade física, a sinalética, a estrutura arquitetónica, as datas e o horário de abertura, a relação com outros postos de informação turística, a atitude hospitaleira, o conhecimento do destino e de outros vizinhos pelos informadores, a partilha e intercâmbio de material promocional com os postos de turismo vizinhos, e a organização, disponibilidade e hospitalidade do espaço. 
imagem global do destino, constituindo-se como uma tecnologia turístico-ideológica que cria representações culturais plurais em confronto e que tentam seduzir os potenciais visitantes (Pereiro e Fernandes, 2018). Neste sentido, a publicidade turística apela a um imaginário de conquista e sedução (Picard e Di Giovine, 2014). Aliás, no campo do turismo fazer promoção é comunicar, criar e projetar imagens para persuadir o consumidor de que o destino é a melhor escolha.

As imagens turísticas tentam vender uma ideia de paraíso na terra que apela a um cliente predisposto a ser seduzido e convencido. Tendem, por isso, a estar cheias de idealizações, tópicos, lugares comuns, estereótipos e preconceitos redutores que não fogem a uma leitura científica crítica (Amirou, 2007). Folhetos, brochuras, panfletos, cartazes, websites, filmes e vídeos turísticos apresentam uma iconografia idílica dos destinos, sendo que na maioria dos casos ocultam, obscurecem e mascaram as realidades sociais, culturais, políticas e económicas (Aurindo, 2006; Selwyn, 1990; 1993, 1996). Assumindo-se como mediações culturais entre os turistas e os recetores, as imagens turísticas servem para vender os locais de destino através da criação de imaginários (Andrade Suárez, 2012; Salazar e Graburn, 2014) que modelam os produtos turísticos como se fossem reais (Crouch e Lübbren, 2003). O papel das brochuras e panfletos na construção dos imaginários turísticos já foi demonstrado por alguns autores (Pereiro e Fernandes, 2018), mas não são os únicos elementos que participam nestes processos. Muitos outros, como os guias de turismo, postais, páginas web, vídeos, filmes, fotografias, a literatura, as redes sociais e as próprias ciências sociais, também são importantes na comunicação e mediação turística.

Nos destinos turísticos, os postos de turismo constituem um elemento central de informação e comunicação com os visitantes (OMT, 1999; Corchero, 2007; Alén et al., 2009; Benabente Espantoso, 2009; Sánchez Vázquez, 2016), procurando dissipar eventuais dúvidas e inquietações, formular recomendações e proporcionar um acolhimento que torne a experiência turística o mais gratificante possível (Izard, 2007). Simultaneamente, são espaços de (re)produção das imagens e experiências do destino. Podem espoletar ligações emocionais e afetivas com o território visitado e são determinantes para proporcionar estímulos aos visitantes para ficarem mais tempo no destino. Os postos de turismo ofereciam, tradicionalmente, informação oral e documental (Hetherington, 1991). De entre a informação básica que ofereciam e ainda costumam oferecer destacam-se os seguintes elementos: folhetos turísticos, calendários de eventos, guias da região, mapas, informação sobre serviços e atrativos turísticos. Com a chegada da sociedade digital e a disseminação da informação online sobre os destinos turísticos, os postos ficaram questionados e reinventaram-se. Em Portugal, tal como em muitos outros países, digitalizaram-se e aumentaram a comunicação audiovisual e digital para com o visitante (De San Eugenio Vela, 2012; Roque et al., 2013). Mas, por outro lado, e paradoxalmente, mantiveram a comunicação oral dos informadores e a informação em papel, pelo que o fator humano continua aqui a ser muito importante (Fernández Arderius, 1999; Araña et al., 2016; Platon, 2017); isto é, a presença de pessoas que façam de mediadores e construam uma cultura de hospitalidade para o visitante. 
Os postos de turismo são definidos na literatura científica mais antiga como centros de informação, geralmente tutelados pela administração pública do Estado, que têm como desígnio fundamental promover os destinos nos mercados (Nolan, 1976; Poon, 1993; Dann, 1996). A sua principal função seria a informativa, de recomendação e serviço ao visitante para melhorar a sua satisfação (Alvarado Corrales, 1995; Fernández Arderius, 1999), seguindo-se outras funções, como as de acolher e ajudar os turistas (Goval, 1996). Seriam, portanto, duas as suas missões principais e tradicionais: a comunicação e o acolhimento e hospitalidade para com o turista (Claude, 1996). Mas esta visão dos anos 1990 na literatura científica foi mudando pouco a pouco até se redefinirem os próprios postos de turismo (Benabente Espantoso, 2009; Panells Costa e Crespi Ballbona, 2002; Sánchez Vázquez, 2016). Assim, Cals, Capella e Vaqué (1998) falam das suas novas funções: gerir serviços de acolhimento dos visitantes e coordenar, promover e comercializar produtos turísticos. Na mesma linha, Galí (2000, p. 84) destaca a existência de quatro objetivos centrais: "Atender, acoger, informar y orientar al visitante durante su estancia; Atender, acoger, informar y orientar al prestatario e intermediario de servicios locales; Coordinar la gestión de los servicios públicos y privados que conforman el producto turístico; Promover y comercializar dichos productos y la oferta turística del destino".

Segundo a perspetiva de Miralbell (2007), os postos também participam na dinamização da oferta de produtos e serviços turísticos, trabalhando em proximidade com produtores e empresários do turismo. Portanto, já não cumprem somente uma função informativa junto dos turistas, como nota Izard (2007, p. 17) ao afirmar que, praticamente, "no existen oficinas que no lleven a cabo tareas de promoción, que no informen al sector local sobre la demanda que les llega, o que no propongan mejoras a las autoridades para aprovechar nuevas oportunidades que han detectado a través del intercambio de información con los turistas, los profesionales, etc". Assim, embora a função informativa e comunicativa seja a mais imediata e relevante - à qual aqui prestaremos maior atenção -, importa ter presente a multivalência e multifuncionalidade dos postos de turismo (Fernandes, Roque e Martins, 2013, pp. 186-187) e o facto de terem múltiplos interlocutores: desde logo, os turistas, mas também o poder local, o sector privado e as autoridades nacionais e regionais do sector. De entre estas novas funções destacam-se as de investigação e análise do perfil dos visitantes, algo muito importante para compreender a procura turística e melhorar a atração do destino e a experiência do visitante.

\section{O TERRITÓRIO DURIENSE E OS SEUS POSTOS DE TURISMO}

O contexto territorial do Douro é ambíguo e conta com uma difícil delimitação (Comissão de Coordenação e Desenvolvimento Regional do Norte, CCDR-N, 2004; Bernardo et al, 2018). No âmbito do projeto de investigação de que resulta o presente artigo consideramos o Douro tal como é circunscrito na Nomenclatura das Unidades Territoriais para Fins Estatísticos, NUTS III (v. fig. 1, em baixo). A sub-região ocupa cerca de $19 \%$ da área da Região Norte de Portugal (86 municípios) ou 4112km² (GEPE, 2011), sendo composta por 19 concelhos (v. fig. 2, em baixo) e "partilhada" por 4 distritos (Vila Real, Viseu, Bragança e Guarda). Trata-se de uma região essencialmente vitivinícola com uma paisagem monumental, declarada como património mundial pela UNESCO, em 2001, na categoria de "paisagem evolutiva viva" (Martins Pereira, 2021). A 
base é a economia vitivinícola que condiciona a paisagem e a vida das suas gentes, embora isso não significa que não haja uma poliatividade na qual se enquadra o turismo (Gonçalves e Guerra, 2018). O papel desta atividade é entendido de diferentes formas por diferentes instituições. Vejamos dois exemplos: a Comunidade Intermunicipal do Douro (CIM Douro) e o Turismo de Portugal. A primeira apresenta os três patrimónios da humanidade durienses (Alto Douro Vinhateiro, Sítios Pré-históricos de Arte Rupestre e Vale do Rio Côa, Olaria Negra de Bisalhães) e motivos para visitar o Douro que se interligam com elementos chave da oferta turística da região. Relativamente à segunda, o Plano Estratégico Nacional de Turismo (PENT), elaborado pela entidade administrativa pública Turismo de Portugal, pensou inicialmente no Douro como um destino de touring cultural (incluindo cruzeiros fluviais), de gastronomia e vinhos e turismo de Natureza. ${ }^{4}$

Figura 1. Mapa da região Norte de Portugal e a sua divisão por NUTS (7. Douro).

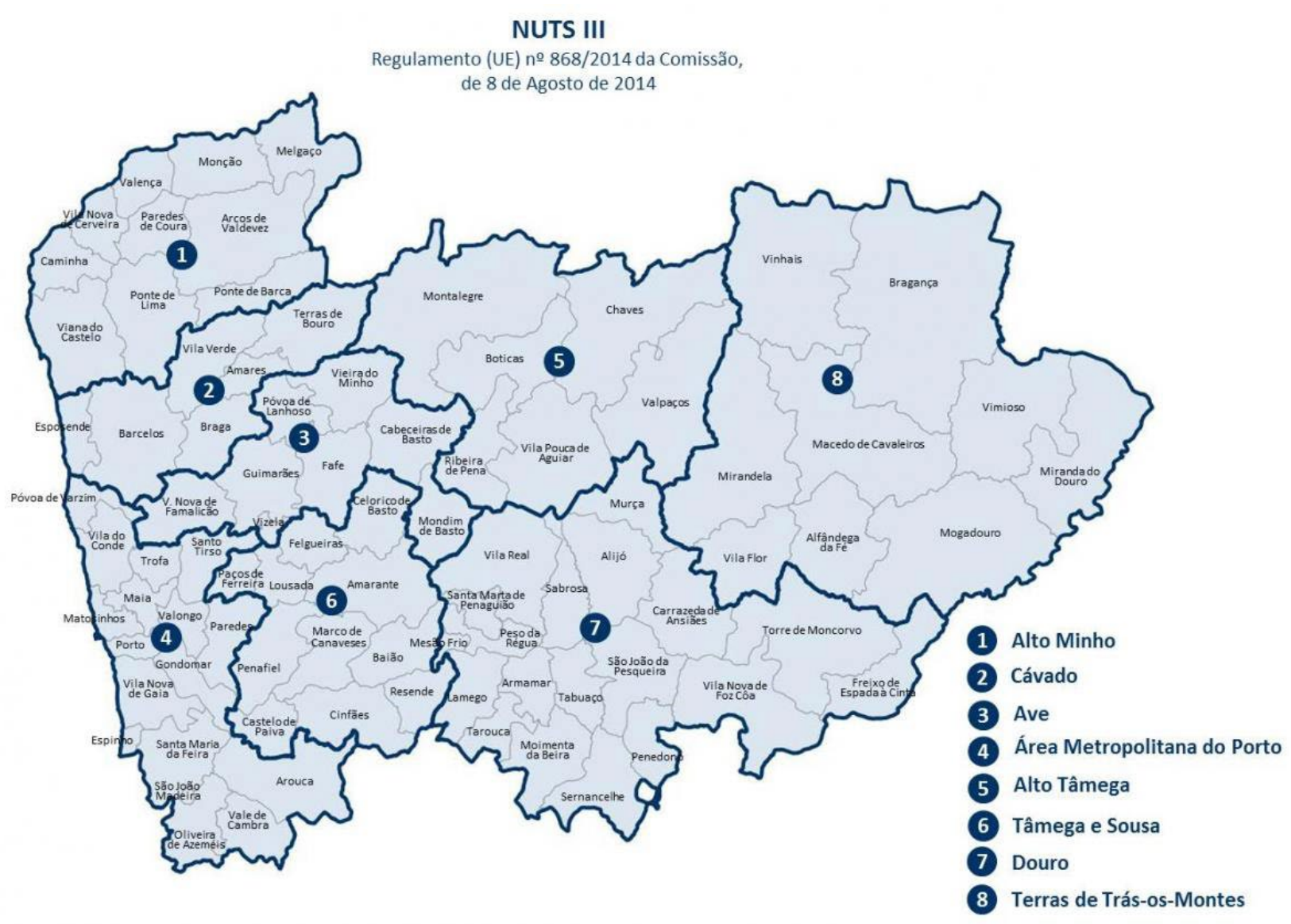

Fonte: CCDR-N (s.d.).

4. Além das potencialidades assinaladas nestas duas conceções, o Douro organiza 75 eventos que podemos afirmar como "turísticos", tais como: a Expodemo, a Feira da Laranja, a Festa da Amendoeira em Flor, as festas religiosas e romarias como a Nossa Senhora dos Remédios, em Lamego, as manifestações rituais como o Entrudo de Lazarim, a Feira Medieval de Penedono, a Feira Medieval de Torre de Moncorvo e eventos com abordagens mais contemporâneas, tais como o Douro Jazz, o Douro Film Harvest, o Douro Entre Margens e, num outro registo, as corridas do Circuito Internacional de Vila Real. 
Figura 2. Mapa da sub-região do Douro

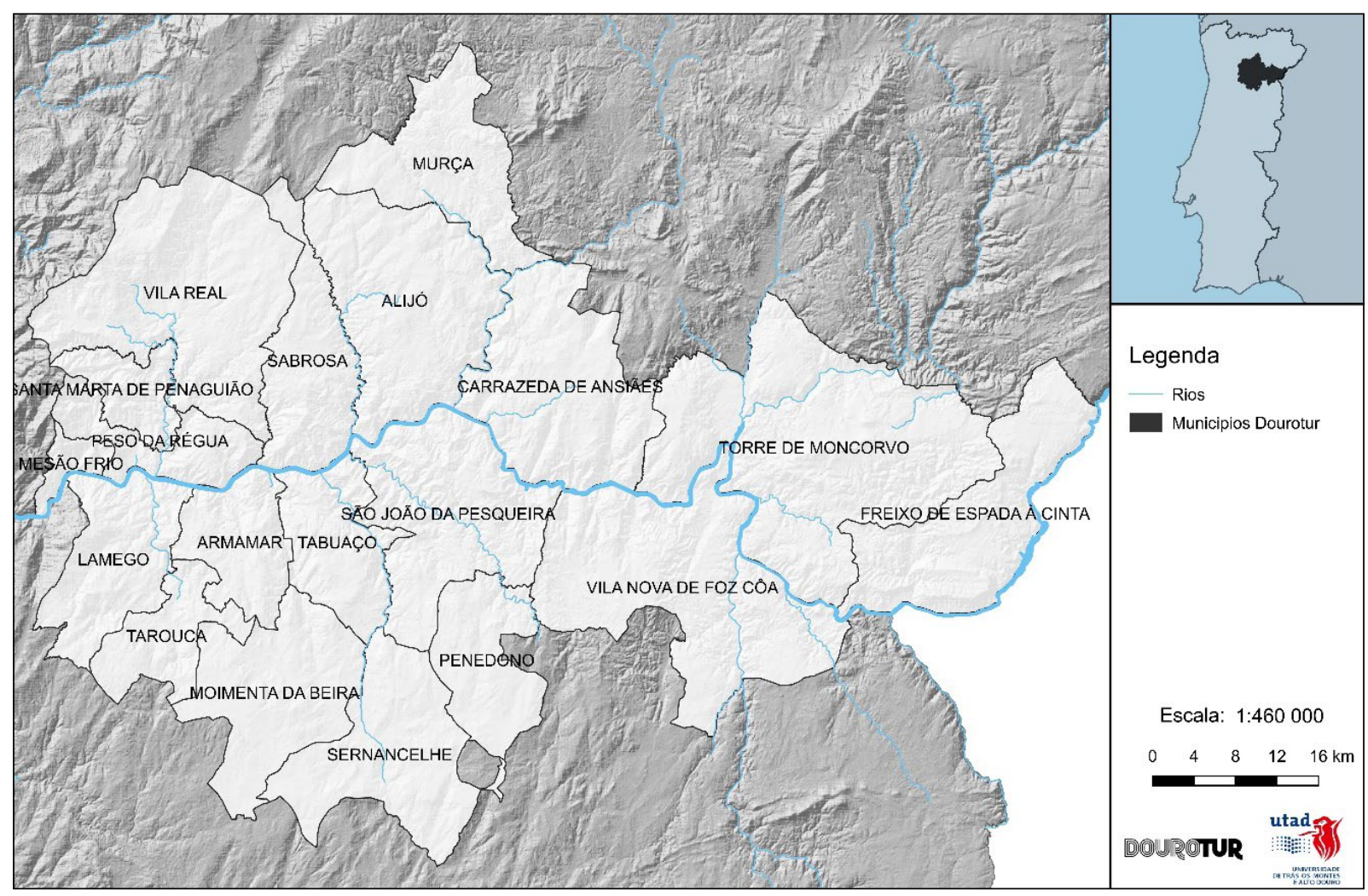

Fonte: Elaborado pelo Prof. Dr. Ricardo Bento (UTAD - CETRAD).

A evolução da oferta de alojamento turístico na região apresenta dados bem significativos. Em 1991, o Douro tinha apenas uma capacidade de alojamento na ordem das 1559 camas, enquanto que em maio de 2019 dispunha já de 8558 camas (Registo Nacional de Turismo RNT, 2019). Em 2017, a região recebeu um total de 250828 hóspedes (Pordata, 2017), sendo que mais de um terço visitou os postos de turismo, segundo as informações estatísticas fornecidas pelos próprios postos, apresentadas mais adiante (tabela 1). Na região há 23 postos de turismo oficiais, que funcionam como centros de informação turística, públicos e com função de serviço público. Tendo em conta os dispositivos de informação e a forma de organização da comunicação, podemos falar em dois tipos de postos de turismo no Douro:

i. os centros de informação turística (CIT), que são geralmente herdeiros dos antigos postos de turismo municipais e correspondem, basicamente, a centros de informação local, oral e documental sobre o município e, em particular, sobre os seus principais pontos de interesse turístico (ex. Mesão Frio, Ucanha, Salzedas, Pinhão, Murça ou Provesende);

ii. as lojas interativas de turismo (LIT), que são uma atualização e renovação dos postos de turismo. Foram criadas a partir de 2012 pelo Turismo do Porto e Norte de Portugal (TPNP) em articulação com os municípios (Domingues Araújo, 2015), criando uma rede regional de 65 lojas. Nelas, a comunicação turística, além de pessoal, verbal e documental, é também audiovisual, digital, mobile, multissensorial e interativa com o visitante. A informação digital nas LIT é alimentada pelos próprios municípios e agentes 
locais, com autorização do TPNP; sendo que a quantidade e a qualidade desta informação revelam assimetrias de município para município. As LIT têm cores unitárias a preto e branco e uma diversidade de cores e símbolos associados aos seus produtos estratégicos. Com grande apoio nas novas TIC, o visitante pode receber informação sobre toda a região Norte de Portugal e não só sobre o município sede da LIT. De forma complementar, as LIT costumam ter no seu exterior um Total Outdoor Media Interative (TOMI), que é uma espécie de totem antropológico; um ponto de informação turística digital e interativo (ex. permite tirar e partilhar fotografias do visitante) que funciona 24 horas com informação sobre a oferta turística e os eventos a decorrer na região Norte de Portugal.

Os postos de turismo são geridos, na maioria dos casos, pelos municípios em articulação com a entidade pública regional do TPNP que envolve os 86 municípios da região Norte de Portugal. ${ }^{5}$ Todos os 19 municípios da região do Douro têm posto ou loja interativa de turismo, inclusive dois (casos de Sabrosa e Alijó) e três (caso de Tarouca), algo que não deixa de indiciar o facto de o turismo já não ser o parente pobre das estratégias de desenvolvimento da região e de se afirmar de forma destacada nos discursos e nas práticas políticas. Mais adiante, na tabela 1, indicamos a localização municipal e a procura turística da maioria destes postos, o que nos mostra, desde logo, diferenças na atração dos fluxos turísticos e algumas desigualdades territoriais particulares.

Em função da sua distribuição geográfica e vocação turística, podemos falar em vários eixos territoriais dos postos de turismo do Douro: o eixo fronteiriço com Castilla y León (Freixo de Espada à Cinta, Vila Nova de Foz Côa e Moncorvo); o eixo interior do Douro (Carrazeda de Ansiães, São João da Pesqueira, Murça, Alijó e Sabrosa); o eixo mais urbano do Douro (Vila Real, Régua e Lamego); o eixo oeste da região (Mesão Frio e Santa Marta de Penaguião); o eixo do Douro Sul, com destaque para os concelhos de Armamar, Tabuaço e Sernancelhe. De um modo geral, os edifícios onde se localizam os postos de turismo são lugares centrais nas localidades, com sinalização específica e costumam ter algum interesse arquitetónico ou artístico para os visitantes, como são os casos de Vila Real, Penedono, Foz Côa ou Moncorvo. Isto é, são por eles próprios atrativos turísticos, quer por serem exemplos de arquitetura tradicional reabilitada quer por se assumirem como estruturas com uma construção apelativa, como é o caso de Peso da Régua, Tarouca e Lamego: “Merece la pena venir para ver solo el edifício" (visitante do posto de turismo de Foz Côa, 52 anos). Deste modo, ir ao posto de turismo é algo mais do que ir à procura de informação. Pode significar também a fruição patrimonial de um emblema arquitetónico.

5. No ano de 2008 foram extintas as antigas regiões de turismo para criar-se, por meio do Decreto-lei 67/2008, as atuais regiões de turismo. 
Tabela 1. Procura turística dos postos de turismo do Douro-NUTS III em 2016

\begin{tabular}{|c|c|c|c|c|c|}
\hline Município & $\begin{array}{l}\text { № total de } \\
\text { visitantes }\end{array}$ & $\begin{array}{l}\text { № visitantes } \\
\text { portugueses }\end{array}$ & $\begin{array}{l}\text { № visitantes } \\
\text { estrangeiros }\end{array}$ & $\begin{array}{l}\% \text { visitantes } \\
\text { portugueses }\end{array}$ & $\begin{array}{l}\% \text { visitantes } \\
\text { estrangeiros }\end{array}$ \\
\hline Alijó & 737 & 287 & 450 & $48,95 \%$ & $61,05 \%$ \\
\hline Pinhão (Alijó) & - & - & - & - & - \\
\hline Armamar & 1005 & 713 & 292 & $70,94 \%$ & $29,06 \%$ \\
\hline Carrazeda de Ansiães & 918 & 837 & 81 & $91,18 \%$ & $8,22 \%$ \\
\hline Freixo de Espada à Cinta & 1732 & 838 & 894 & $48,38 \%$ & $51,62 \%$ \\
\hline Lamego & 17467 & 6281 & 11186 & $35,96 \%$ & $64,04 \%$ \\
\hline Mesão Frio & 691 & 430 & 261 & $62,22 \%$ & $37,77 \%$ \\
\hline Moimenta da Beira & - & - & - & - & - \\
\hline Murça & - & - & - & - & - \\
\hline Penedono & - & - & - & - & - \\
\hline Peso da Régua & 22347 & 4597 & 17750 & $20,58 \%$ & $79,52 \%$ \\
\hline São João da Pesqueira & 4670 & 3939 & 731 & $84,34 \%$ & $15,66 \%$ \\
\hline Sabrosa & 774 & 246 & 528 & $31,78 \%$ & $68,22 \%$ \\
\hline Provesende (Sabrosa) & 2193 & 592 & 1601 & $26,99 \%$ & $73,01 \%$ \\
\hline S. Marta de Penaguião & 299 & - & - & - & - \\
\hline Sernancelhe & 1751 & - & - & - & - \\
\hline Tabuaço & 2481 & 1443 & 1038 & $58,16 \%$ & $41,84 \%$ \\
\hline Torre de Moncorvo & 5154 & 3987 & 1167 & $77,35 \%$ & $22,65 \%$ \\
\hline Tarouca & - & - & - & - & - \\
\hline Ucanha (Tarouca) & - & - & - & - & - \\
\hline Salzedas (Tarouca) & - & - & - & - & - \\
\hline Vila Nova de Foz Côa & 15762 & 9735 & 6027 & $62 \%$ & $38 \%$ \\
\hline Vila Real & 11774 & 4733 & 7041 & $40,19 \%$ & $59,81 \%$ \\
\hline TOTAL & 89755 & 38658 & 49047 & $43,07 \%$ & $54,63 \%$ \\
\hline
\end{tabular}

Fonte: Elaboração própria com base em dados fornecidos pelos postos de turismo. Faltam os dados de Pinhão (Alijó), Moimenta da Beira, Murça, Penedono, Ucanha e Salzedas (Tarouca).

Quanto à procura, evidenciam-se desde logo dois aspetos: (i) cerca de 90000 visitantes procuraram os postos de turismo do Douro em 2016 e 54,63\% deles eram estrangeiros, sendo que, no total do fluxo de visitantes do Douro, os turistas estrangeiros representam apenas cerca de $25 \%$ (cf. https://www.pordata.pt/); (ii) os postos de turismo mais procurados no Douro são Peso da Régua, Lamego, Vila Nova de Foz Côa e Vila Real, por esta ordem. Em segundo lugar, os de procura média-baixa são Torre de Moncorvo, São João da Pesqueira, Tabuaço, Provesende e Freixo de Espada à Cinta. Em terceiro lugar, os de procura baixa são Armamar, Carrazeda, Sabrosa, Alijó, Mesão Frio, Santa Marta de Penaguião e Murça. Em praticamente todos eles, a procura é bastante sazonal, concentrando-se, sobretudo, nas férias da Páscoa e nos meses do verão europeu, de junho a setembro. Por outro lado, esta mesma procura deixa transparecer uma certa hierarquia na atratividade dos vários municípios e também diferentes vocações turísticas no território Douro. Os postos de turismo com maior afluência são os dos 
municípios mais próximos e ligados ao turismo fluvial do rio Douro, também mais procurado por estrangeiros.

\section{ASSIMETRIAS E CONSTRANGIMENTOS ESTRUTURAIS DOS POSTOS DE TURISMO DO DOURO}

Considerando a distribuição geográfica dos postos de turismo no Douro, há a destacar, desde logo, os que se situam no eixo mais urbano da região: Vila Real - Rgua - Lamego. São, indiscutivelmente, os que concentram um maior volume de visitas (Tabela 1, atrás). Por outro lado, pelo próprio espaço físico, organização e dinâmicas, são aqueles que melhor deixam transparecer a importância e centralidade do turismo na agenda política municipal. De um modo geral, são aqueles que mais se aproximam dos critérios que Alén et al. (2009) identificam como necessários para que um posto de informação turística tenha aquilo que designam por "eficácia ótima": "Además de tener la información y el personal adecuados, debe contar con la ubicación apropiada para que cualquier persona pueda acceder a él sin dificultad; pero si a todo esto se le añade el estar situado en un lugar donde el visitante pueda obtener información adicional, mejora su función ostensiblemente" (Alén et al., 2009, p. 553). Referindo-se à LIT de Lamego, o registo etnográfico que se segue mostra, justamente, que o posto em causa cumpre a generalidade dos critérios atrás mencionados, evidenciando a existência de uma preocupação clara em proporcionar um espaço de acolhimento (físico e social) cuidado e aprazível aos visitantes:

A LIT foi aberta em 30 de abril de 2016, num edifício feito de ferro enveIhecido, com sala de provas de vinhos-bar ainda sem funcionar. A guia que nos atendeu era uma mulher de aproximadamente 50 anos. Deu-nos uma boa explicação do turismo local, detalhada e com calma. Tinham um registo de visitantes com os seguintes dados: número, data, assinatura, motivo da viagem e grau de satisfação da informação. O local da LIT é amplo, grande, espaçoso, com cadeiras para estar e sentar-se, luminoso, com rampa de entrada para turismo acessível. A guia registou os horários dos principais atrativos de Lamego e deu-nos informação dos municípios vizinhos, utilizou plantas, mapas, folhetos, computador, Google-maps. Há um TOMI no exterior da LIT e também um bom estacionamento para carros. Está localizado cerca do Museu de Lamego, do teatro, da Sé Catedral e do centro histórico (Diário de campo XP, Lamego, 9-12-2017).

Fora deste eixo mais urbanizado e turistificado da região duriense, há alguns postos de turismo que também cumprem critérios básicos de qualidade, nomeadamente em termos de acolhimento e informação. É este o caso de Vila Nova Foz Côa, com uma significativa procura turística, fruto da dinamização e atratividade suscitadas pela elevação das gravuras rupestres paleolíticas a património mundial da UNESCO. A sua LIT oferece informação do município, da sub-região do Douro e da região Norte de Portugal de forma articulada, sobretudo através de informação oral, digital e audiovisual. Neste mesmo eixo territorial fronteiriço com Espanha, encontra-se o posto de turismo de Torre de Moncorvo, também com uma oferta de serviços ao visitante muito completa na sua LIT, ainda que os dados disponíveis no TOMI apresentem algumas lacunas, nomeadamente sobre gastronomia local e estabelecimentos de restauração: 
Visita ao novo posto de turismo, que abriu em 2014. Levantamos folhetos e combinamos visita guiada para o dia seguinte pelas 10:30 horas. 0 informador era um homem. É um posto de turismo municipal convertido em LIT em articulação com TPNP. Tem boa sinalética. O informador chegou a afirmar que "os galegos percebem português". Ofereceu-nos uma planta e destacou nela a catedral e o museu do ferro. Os horários do posto estão públicos na porta da fachada do edifício rosado, bem visível. Há um TOMI em funcionamento nas proximidades do posto, mas sem informação sobre restaurantes em Torre de Moncorvo, o que mostra os problemas de alimentação de informação deste sistema (Diário de campo XP, Torre de Moncorvo, 4-01-2019).

Um dos informadores turísticos deste mesmo posto afirmou o seguinte durante uma visita guiada pelo centro histórico de Torre de Moncorvo: "O que queremos é que a gente venha, fique satisfeita, fale bem e de nós e envie mais gente" (Diário de campo XP, 5-01-2019). Além de se conferir importância à comunicação de informação de promoção turística (por via oral, documental e digital), este discurso mostra-nos que, no decurso do processo de acoIhimento de turistas, procura-se ainda contemplar uma dimensão relacional, no sentido de assegurar a sedução dos visitantes e o seu envolvimento pessoal/emocional. Este "marketing relacional" (Fyall, Callod e Edwards, 2003) é importante por duas grandes razões: (i) contribui para uma possível vinculação ao destino (place attachment) e, eventualmente, para uma relativa lealdade turística (Prayag e Ryan, 2012); (ii) potencia a promoção turística difusa do contexto no formato da recomendação informal boca-a-boca (Phillips et al., 2013; Swanson e Hsu, 2009).

Alguns dos postos, mesmo aqueles situados em concelhos que poderão ser considerados um pouco mais "periféricos" no contexto turístico duriense, procuram articular a ampla disponibilidade em termos de horários, o envolvimento social assegurado pelos funcionários que recebem os turistas e as novas tecnologias de informação e comunicação como fatores que lhes permitem funcionar, efetivamente, como espaços de informação, orientação e acoIhimento. Ainda que sem dispensar a interação pessoal, a modernização tecnológica é, aliás, uma marca incontornável (e tendencialmente globalizada) nos processos e práticas de receção e aconselhamento de turistas (Schmidt-Rauch, Fux e Schwabe, 2011), como já foi possível constatar em registos anteriores e como é, de igual modo evidente, nos casos dos postos de turismo de Tabuaço, Armamar e Penedono, referenciados nas vinhetas etnográficas que se seguem:

Loja interativa, num jardim central, bem situado, localizado e sinalizado. Fomos recebidos por uma mulher de uns 50 anos aproximadamente, que nos explicou de forma pormenorizada e com muita paixão tranquila os pontos de interesse do município, com apoio de plantas, mapas, caneta e mesa interativa. O TOMI fica fora do posto, 24 horas ligado. $O$ interior do edifício era uma antiga escola e cantina, que também alberga um relógio artesanal feito por um local. A loja abre todos os dias (Diário de campo XP, Tabuaço, 9-12-2017).

Visitamos a LIT, onde estava o técnico H., que nos mostrou o rés-do-chão e a loja-gourmet com produtos locais. A LIT encontra-se num edifício novo de 
dois andares. Tem uma mesa interativa, um ecrã gigante com promoção turística audiovisual do Norte de Portugal, um balcão de atendimento ao fundo, uma estante com folhetos e pequenas montras com produtos locais e souvenirs regionais. [...] A LIT de Armamar abre todos os dias do ano. Só fecha 2-3 feriados. Tem um TOMI no jardim, a funcionar corretamente. Promovem também o restaurante de Rui Paula (Diário de campo XP, Armamar, 10-03-2019).

Localizada ao pé do castelo. Recebeu-nos uma informadora, mulher de 40 anos aproximadamente, no rés-do-chão do edifício de dois andares. Ofereceunos muita informação sobre o que ver e fazer em Penedono. Recomendou-nos a visita ao castelo, e disse-nos que era gratuita. Vendeu-nos postais antigos a $0,30 €$ cada. Explicou-nos onde comer e lamentou que ontem à noite estivessem alguns restaurantes fechados. [...] No primeiro andar estava a mesa interativa. A informadora explicou-nos como funcionava e permitiu-nos levantar folhetos. Ali também havia um filme promocional da região Norte de Portugal que passava num grande ecrã. O discurso da oferta foi o do património histórico e arqueológico: castelo, Idade Média, antas, menires, festa medieval, igrejas, capelas... (Diário de campo XP, Penedono, 9-03-2019).

Apesar da crescente preocupação da generalidade dos municípios em investir na promoção dos respetivos territórios e em criar condições para receber os turistas que os visitam, ainda são muitos os postos de turismo que enfrentam vários e acentuados constrangimentos estruturais, tais como: condicionamentos sazonais e limitações de horários de receção pessoal dos visitantes, falta de recursos humanos especializados para atendimento e aconselhamento, inadequação do espaço e da sua sinalização, deficiências na estrutura e/ou nos dispositivos de informação, entre outros. Nalguns casos, os postos estão encerrados ao fim-de-semana, que é quando mais visitantes acorrem ao Douro. De seguida, mostramos uma ampla série de exemplos etnográficos do nosso trabalho de campo a evidenciar a considerável transversalidade destes problemas que acabam por condicionar de forma decisiva a qualidade do acolhimento e a comunicação com os visitantes:

Posto de turismo fechado, apesar de no timetable e na internet se afirmar que estava aberto aos fins-de-semana (Diário de campo XP, Sernancelhe, 9-03-2019).

Posto de turismo fechado aos fins-de-semana. TOMI no exterior sem funcionar (Diário de campo XP, Moimenta da Beira, 9-03-2019).

$\mathrm{Na}$ aldeia há um posto de turismo, mas hoje, domingo, encontra-se fechado. Segundo uma vizinha (70 anos, aproximadamente), a pessoa que recebe os turistas é um rapaz da aldeia. Abre de segunda a sábado e pagam-lhe de Tarouca, diz-me. O posto é uma cabana de madeira com alguma informação sobre a aldeia, sinalética, mapas e alguma interpretação (Diário de campo XP, Ucanha, 10-03-2019). 
O posto de turismo estava fechado, ainda que a informação oficial na porta indicava que devia estar aberto. Situado no mercado e mau sinalizado. Alguns locais nem sabiam onde era (Diário de campo XP, Tarouca, 9-12-2017).

Loja interativa no jardim central. Só abre de 2a a 6a em horário de expediente (documento da Câmara Municipal colado na entrada), mas a informação oficial do TPNP é de que abre de $2^{2}$ a domingo. Sem TOMI no exterior (Diário de campo XP, Santa Marta de Penaguião, 10-12-2017).

Posto de turismo com problemas de sinalética. Fechado. Só abre de $2 \mathfrak{a}$ a 6a em horário de expediente (Diário de campo XP, Alijó 8-12-2017).

Só abre em março. Fomos informados por uma senhora (50 anos, aproximadamente) e um senhor (55 anos, aproximadamente) de que estavam em negociações com o TPNP para criar uma loja interativa (Diário de campo XP, Pinhão, 8-12-2017).

Posto de turismo municipal fechado. Só abre de 2a a 6a feira, das $9 \mathrm{~h}-13 \mathrm{~h}$ e das 14h-17h. Pequeno, quase sem informação documental, situado no largo principal da vila, sem TOMI no exterior (Diário de campo XP, Mesão Frio, 10-12-2017).

Na vila visitei o posto de turismo municipal aberto em 2000 com verbas do programa Leader (EU). Recebeu-me uma informadora com cerca de 45 anos. Respondeu à minha questão sobre o que fazer e que atrações turísticas há em Murça da seguinte forma: "Aqui não há nada". Logo de seguida ofereceu-me alguns folhetos e postais. O horário está afixado na porta: o posto abre todos os dias. A informadora comentou-me o mapa do concelho, destacou a Porca de Murça, um castro, duas igrejas, o mural de azulejos do concelho, a visita à adega e dois alojamentos rurais em quintas. No posto oferecem visitas guiadas pela pequena vila e pelo concelho. Tem alguns produtos, mas só para exposição. Além de alguma informação local, só existe um folheto da região Norte e outro de um hotel de Lisboa. No mapa estampado do município predominam os elementos patrimoniais históricos. A informadora disse-me que trabalha com outra colega e que têm alguns estagiários de uma escola profissional a trabalhar com elas. Referiu ainda que este ano iam mudar para a nova LIT, ao pé do jardim, já com tudo digital e em rede. Recolhem informação em papel sobre o perfil do visitante, idade, nacionalidade e motivação da visita. Durante este mês de maio, o posto teve 7 visitantes, muitos estrangeiros (Diário de campo XP, Murça, 22-05-2019).

Os evidentes condicionalismos de horários existentes na generalidade destes postos de turismo - tal como em muitos outros de outros contextos portugueses (Fernandes et al., 2013) -, os problemas de localização, espaço e sinalética existentes nalguns, e a inexistência em quase todos de dispositivos digitais informativos exteriores, condicionam, profunda e negativamente, a eficácia das suas funções. Aliás, a estreita limitação de horários, aliada à escassez de informação que possa ser obtida quando os postos estão fechados, têm um impacto negativo, imediato e a médio/longo prazo, na procura turística, como concluem Alén et al. (2009, p. 563): "la mayoría de visitantes pueden llegar a la ciudad tarde, buscando información 
general de la región y, en particular, detalles sobre alojamiento y restauración. Si esta información no está disponible los visitantes podrían limitar la cantidad de tiempo que pasan en la región o pueden elegir no visitar nada dentro de ella". Além do mais, tal situação acaba por ter uma repercussão bastante negativa no marketing boca-a-boca, influenciando pela negativa potenciais futuros visitantes. Geralmente, os responsáveis locais, nomeadamente a nível das autarquias, invocam o escasso volume de fluxos turísticos para (tentar) justificar os horários e, em certa medida, as próprias lacunas existentes nas funções informativas consignadas aos postos de turismo. Provavelmente, deveriam inverter os nexos de causalidade e procurar aferir se a própria escassez de visitantes não é, pelo menos em parte, resultante dos muitos constrangimentos que afetam o sistema local de acolhimento e informação turística.

\section{ACOLHIMENTO E COMUNICAÇÃO TURÍSTICA}

Os postos de turismo do Douro evidenciam uma certa recorrência nas suas estruturas e elementos informativos: balcão com computadores e algum folheto, planta ou mapa; zona de exposição e, nalguns casos, prova de produtos locais; zona de exposição de folhetos, guias, roteiros e mapas em suporte papel; zona de projeção audiovisual (promoção e divulgação turística); mesa interativa com informação sobre a região Norte de Portugal. Alguns deles apresentam também uma caixa multibanco, como é o caso do de Barca de Alva (concelho de Figueira de Castelo Rodrigo, na fronteira da região do Douro NUT-III), e praticamente todos estão adaptados e preparados para pessoas com mobilidade reduzida. A polivalência permite-Ihes assumir, entre outras, funções de hospitalidade, acolhimento e receção de visitantes, mediação, orientação, informação (presencial, telefónica, audiovisual, documental e digital) e comunicação da oferta turística do destino. A função de difusão de informação é particularmente relevante, pois o turismo é uma área na qual a comunicação é um elemento essencial (Dann, 1996). Embora se considere, por vezes, que "a informação é muita e não é preciso ir à LIT" (homem, 20 anos, estagiário, posto de turismo de Vila Real, 26-10-2016), a realidade é que os visitantes continuam a frequentar de forma muito expressiva os postos de turismo da região do Douro (Tabela 1, atrás). Além de difusores de informação, também apresentam outras funções complementares, como a exposição de elementos culturais e patrimoniais do município onde estão inseridos e a interpretação do património natural e cultural do contexto que servem. São, portanto, uma mostra de forma(s) de experienciar o destino turístico, induzindo modos de olhar a paisagem e de estabelecer vínculos multissensoriais com os territórios. Constituem, assim, um poderoso elo de ligação entre os locais e os visitantes, o local e o global; daí que sejam verdadeiras portas de entrada da região e não apenas janelas ou montras.

A maioria dos técnicos que presta informações nos postos de turismo do Douro são funcionários públicos das autarquias. Embora nem todos apresentem formação académica ou técnico-profissional específica na área do turismo, as autarquias têm vindo, de um modo geral, a fazer um esforço no sentido de colmatar esta lacuna, como é o caso de Murça, segundo uma das funcionárias (cerca de 35 anos) do respetivo posto: "Já está prometido pela Câmara formações em turismo". Alguns dos trabalhadores dos postos de turismo são também estudantes de turismo em estágio, das escolas profissionais, dos institutos politécnicos ou do ensino superior 
universitário. Estes estudantes reconhecem abertamente a importância das competências linguísticas e a fluência em línguas estrangeiras no seu trabalho: "O inglês é a língua oficial do turismo" (homem, 20 anos, estagiário, posto de turismo de Vila Real, 26-10-2016); "O inglês e o espanhol não são suficientes para uma loja interativa de turismo" (mulher, 20 anos, estagiária, posto de turismo de Vila Real, 26-10-2016). A maioria dos profissionais de informação turística que nos recebeu é do sexo feminino. De um total de 55, 40 (73\%) são mulheres e 15 (27\%) são homens, o que mostra o predomínio do género feminino na profissão de informadores turísticos na região do Douro. Aliás, em 7 municípios só há mulheres a prestar os serviços de informação turística.

A nossa observação permitiu-nos comprovar as competências relacionais e linguísticas dos informadores perante os visitantes, sendo percetível um padrão que, de forma resumida,

se pode caracterizar a partir das seguintes dinâmicas: se o visitante fala em espanhol, tentam falar em espanhol, ou melhor, em portunhol; se o visitante fala em inglês, dirigem-se a ele em inglês; se o visitante fala português, o informador também; se o visitante fala galego, o informador pode falar em português, nalguns casos, em portunhol e, em menor medida, em espanhol; Também há informadores que falam em português para espanhóis. Embora persistam algumas lacunas nas competências linguísticas, estes profissionais são um elemento central do processo de informação turística. Nalguns casos, sobretudo em municípios mais pequenos e com menor vocação turística, este processo fica comprometido, em virtude da escassez de recursos humanos para manter o posto aberto aos fins-de-semana, mesmo nos períodos da época turística alta. Como já pudemos constatar, este é um problema estrutural comum a muitos postos de turismo da região.

E o que perguntam ou querem saber os visitantes? Respondemos a esta questão através de uma vinheta etnográfica ilustrativa, referente ao posto de turismo de Vila Real. Nesta LIT, situada na antiga Casa dos Marqueses, um lugar central na Avenida Carvalho Araújo, os visitantes costumam ter mais de 40 anos e perguntam pela Casa de Mateus (palacete barroco próximo da cidade), pelo Douro, pelo Parque Natural do Alvão, pelas Fisgas de Ermelo, pela Sé de Vila Real, por hotéis e por restaurantes. Os visitantes levam mapas, postais, roteiros e agendas de eventos locais. Neste posto as questões mais frequentes são como chegar aos pontos de interesse turístico, os horários e onde comer e dormir. É de sublinhar aqui uma diferença entre dois tipos de comunicação: a comunicação presencial no próprio posto e a comunicação através de telefone, que é relativamente habitual entre os informadores e os visitantes. Neste segundo tipo de comunicação, os diálogos são, essencialmente, sobre os horários dos museus, do próprio posto e das visitas ao centro histórico de Vila Real, ao Palácio de Mateus e ao Santuário de Panóias. Os turistas também solicitam informação sobre visitas guiadas, contatos de alojamento e restauração, e informações sobre a olaria preta de Bisalhães, as quintas, as vindimas, os prestadores de serviços turísticos, as festas e os pontos de interesse turístico na região.

E que é oferecido nos postos de turismo do Douro? A análise dos dados coletados pelos investigadores que acederam aos postos como clientes-mistério permitiu-nos detetar alguns problemas de comunicação turística do ponto de vista da oferta, o que, em conjunto com os constrangimentos estruturais já identificados, acaba por condicionar negativamente o processo 
de acolhimento. É de destacar i) o escasso domínio de línguas estrangeiras nalguns dos postos de turismo; ii) a oferta de informação ser concebida desde o ponto de vista da oferta e não desde o enfoque do turista e das suas necessidades; iii) a falta de material impresso nalguns casos, especialmente nos postos que não integram a rede de LIT do TPNP; iv) a ausência, por vezes, de material informativo e interpretativo sobre flora e fauna do município e da região; v) o facto de nem todos os postos oferecerem informação turística dos municípios vizinhos; vi) o relativo desconhecimento da oferta turística dos municípios vizinhos por parte de alguns informadores, reconhecido pelos próprios nalgumas entrevistas. A propósito destas fronteiras e desarticulações de informação entre municípios do Douro NUT-III, vejamos de seguida o exemplo do posto municipal de turismo de Freixo de Espada à Cinta, que, paradoxalmente, oferece mais informação turística sobre o lado espanhol com o qual confronta do que sobre a região do Douro português:

O posto está situado no edifício da biblioteca municipal, com boa sinalética exterior. No exterior do posto, um placar eletrónico-digital (com a etiqueta "Hecho en España") com informação turística da zona, dos dois lados da raia. No interior do posto, começou por falar P., em espanhol, perguntando pelo que fazer e ver em Freixo. A informadora, mulher de uns 55 anos, respondeu em espanhol com sotaque português, após levantar-se da sua cadeira e arranjar uma planta de Freixo (vila). Assinalou nela a igreja, o castelo, o museu da Seda e o museu Guerra Junqueiro. Disse-nos que só informava de Freixo e não de outros municípios, e que estava tudo lá no mapa (Diário de campo XP, Freixo de Espada à Cinta, 2-01-2019).

Alguns postos oferecem serviços de visita guiada gratuita (geralmente por marcação), muito apreciados pelos visitantes, como, por exemplo, os casos de Vila Real, Armamar, Murça ou Torre de Moncorvo. Nestes casos, a comunicação turística com o visitante prolonga-se algo mais no tempo, é menos esporádica e passageira, e permite um maior interconhecimento entre visitantes e guia, constituindo-se este último como representante e espelho cultural da comunidade local.

Outro elemento importante da comunicação turística destes postos é a (in)coerência territorial da mensagem turística que passam do município, da região do Douro, do Norte de Portugal e de Portugal. Em cada posto são veiculadas imagens turísticas locais, regionais e nacionais, ainda que nem sempre devidamente articuladas. O TPNP tem feito um esforço muito significativo de coordenação e hierarquização da imagem turística integrada da região Norte de Portugal. É disto exemplo a representação iconográfica dos quatro patrimónios da Humanidade existentes nesta região (dois deles localizados no Douro), com fundo a preto e, a realçar, o ícone em branco: o Centro Histórico de Guimarães (arcada da porta de entrada da cidade); o Alto Douro vinhateiro (barco rabelo); o Centro Histórico do Porto (ponte D. Luiz I); e, por último, o Vale do Côa (cervo). Todavia, ainda persistem forças centrífugas que levam a criar uma imagem turística muito diversificada e, geralmente, pouco congruente, de município para município. A tabela 2, em baixo, dá conta desta ampla heterogeneidade, elencando os vários slogans turísticos promocionais dos municípios do Douro, constantemente reafirmados nos respetivos postos de turismo. 
Tabela 2. Slogans de promoção turística dos municípios da região do Douro

\begin{tabular}{|c|c|c|}
\hline Município & Slogan & Web \\
\hline Alijó & $\begin{array}{l}\text { Território de origem demarcada; } \\
\text { Coração do Alto Douro Vinhateiro }\end{array}$ & http://www.cm-alijo.pt/ \\
\hline Armamar & $\begin{array}{l}\text { Terra de emoções; } \\
\text { Capital da maçã de montanha }\end{array}$ & http://www.cm-armamar.pt/ \\
\hline Carrazeda de Ansiães & Património, paisagens e história & $\begin{array}{l}\text { https://www.cm- } \\
\text { carrazedadeansiaes.pt/ }\end{array}$ \\
\hline $\begin{array}{l}\text { Freixo de Espada à } \\
\text { Cinta }\end{array}$ & Terras de seda; Onde o Douro começa & $\begin{array}{l}\text { http://www.cm-freixoespadacinta. } \\
\text { pt/ }\end{array}$ \\
\hline Lamego & Lamego é Douro; Cidade com história & https://www.cm-lamego.pt/ \\
\hline Mesão Frio & Porta do Douro & http://www.cm-mesaofrio.pt/ \\
\hline Moimenta da Beira & Terras do Demo; Douro & http://www.cm-moimenta.pt/ \\
\hline Murça & Oito séculos de história & https://www.cm-murca.pt/ \\
\hline Penedono & Memória dos tempos medievais & https://cm-penedono.pt/ \\
\hline Peso da Régua & Cidade do vinho 2019 & https://www.cm-pesoregua.pt/ \\
\hline S. João da Pesqueira & Coração do Douro vinhateiro & https://www.sjpesqueira.pt/ \\
\hline Sabrosa & Terra de Fernão Magalhães & https://www.sabrosa.pt/ \\
\hline S. Marta de Penaguião & Santa Marta COM VIDA - CONVIDA & https://www.cm-smpenaguiao.pt/ \\
\hline Sernancelhe & Terra da castanha & http://www.cm-sernancelhe.pt/ \\
\hline Tabuaço & Segredos do Douro & http://www.cm-tabuaco.pt/ \\
\hline Torre de Moncorvo & 365 dias à sua espera & http://www.cm-moncorvo.pt/ \\
\hline Tarouca & Vale Varosa & https://www.cm-tarouca.pt/ \\
\hline Vila Nova de Foz Côa & Um concelho, dois patrimónios mundiais & https://www.cm-fozcoa.pt/ \\
\hline Vila Real & Tradição e futuro & http://www.cm-vilareal.pt/ \\
\hline
\end{tabular}

Fonte: Elaboração própria com base no trabalho de campo realizado.

No nosso entender, estes slogans tão diferenciais mostram uma certa paroquialização e competição entre vizinhos, o que acaba por inibir a construção de estratégias cooperativas e o desenvolvimento de uma marca Douro consistente e flexível, capaz de refletir, em simultâneo, os denominadores comuns e as especificidades concelhias. É fundamental não esquecer que um destino turístico vale mais do que a totalidade das suas partes e é, seguramente, algo mais do que a soma de partes. Para além disto, e perante a profusão pouco criteriosa de representações turísticas dos municípios durienses, importa ter em conta que, desde meados do século XIX, a imagem dominante nos guias turísticos e outros materiais de promoção da região do Douro é a de um contexto vinhateiro, com uma paisagem grandiosa e imponente (Santana, 2017). É legítimo, por isso, admitir-se que esta imagem dominante e com uma ampla espessura histórica poderia ser o grande eixo agregador, em torno do qual as demais imagens e particularidades locais seriam articuladas e projetadas. 


\section{CONSIDERAÇÕES FINAIS}

Os postos de turismo são elementos essenciais da comunicação e mediação turística de um destino, sendo que a sua organização e gestão exige evidentes esforços organizacionais, financeiros e humanos. Na região do Douro e, de um modo geral, em todo o Norte de Portugal, as LIT representam um recente paradigma de comunicação turística digital, funcionando em interconexão e de modo padronizado, embora ainda subsistam postos de turismo municipais, classificados por nós como CIT, que funcionam de forma mais autárcica e desconexa. Na execução regional deste novo paradigma digital, assente na magia tecnológica, na interatividade e na informação em rede (Castells, 1997; 1999), o contacto interpessoal e a comunicação verbal em presença por parte dos funcionários dos postos de turismo não deixam de ter uma incontornável relevância, assumindo uma importância decisiva no sucesso do acolhimento turístico. A análise que desenvolvemos ao longo deste texto mostra, justamente, que os fatores humanos da comunicação são essenciais para a eficácia da transmissão de informações sobre o destino, para a sua interpretação e descodificação pelos turistas e, de um modo geral, para a concretização de uma experiência mais envolvente e vinculativa que pode mesmo suscitar a fidelização dos visitantes.

Além da capacidade técnica para se construir um quadro de proximidade intersubjetiva no processo de acolhimento, a qualidade da mediação entre a oferta e a procura turística depende também, a montante e a uma escala mais estrutural, da organização e funcionamento dos postos de turismo. No caso da região do Douro, como pudemos constatar, muitos destes postos ainda evidenciam sérios constrangimentos estruturais que acabam por comprometer o seu papel na gestão da comunicação e por gerar afastamentos e desfasamentos entre o destino e os visitantes. De entre esses constrangimentos, destacamos os seguintes: i) horários diferentes segundo os municípios e, nalguns casos, os postos estão fechados aos fins-de-semana, que é o período de maior procura da região; ii) relativa escassez de recursos humanos, sobretudo com formação específica em turismo; iii) a negligência e demora, por vezes, na manutenção do sistema de informação turística digital exterior (TOMI) das LIT; a recolha de informação sobre os visitantes dos postos de turismo da região tende a ser feita de forma desigual, pouco criteriosa e desarticulada, sendo necessário construir um sistema uniforme e integrado de recolha digital de dados que permita comparar e melhor conhecer os visitantes para, assim, se poderem tomar decisões estratégicas mais pertinentes; iv) as mesas interativas dos postos estão conectadas em rede pelo TPNP, mas a gestão, alimentação e atualização da informação de cada município é feita de forma descentralizada à escala municipal, o que exige mais esforço de articulação a vários níveis, sobretudo para se assegurar congruência e complementaridade das múltiplas imagens turísticas projetadas desde a região.

O novo modelo de comunicação turística integrada e em rede, impulsionado pelo TPNP, remete, em teoria, para a ideia de que o todo suplanta a soma das partes, passando-se de uma lógica comunicacional de um a todos (modelo linear informativo e promocional) para outra de todos a todos (Gomis, 2009), que, apesar de muito dependente da digitalização de processos, não pode descurar a comunicação pessoal e presencial interligada com a persuasão e a emoção. No caso que aqui considerámos ainda não se atingiu um nível de integração e reticularidade suficiente para uma comunicação não fragmentada e coerente que envolva toda a 
região do Douro na estratégia comunicacional do destino. Por outro lado, no que toca à importância de relativizar a competência da tecnologia e de humanizar o acolhimento turístico, foi possível verificar que em alguns postos de turismo há uma preocupação explícita em fomentar proximidade e intersubjetividade com os visitantes. Noutros, nem tanto. Justificar-se-á, por isso, um maior investimento dos municípios na formação dos técnicos dos postos turísticos e na sensibilização para a importância do seu papel enquanto promotores de confiança, convergência intercultural, mediação e empatia-simpatia entre o destino e os respetivos visitantes, contribuindo, assim, para algo que é fundamental ao turismo: uma cultura de acolhimento e hospitalidade.

\section{REFERÊNCIAS BIBLIOGRÁFICAS}

Alén González, M. E., Fraiz Brea, J. A. e Rodriguez Comesaña, L. (2009). Análisis de los determinantes del uso de fuentes de información previas al viaje y de las oficinas de turismo en destino. Estudios y Perspectivas del Turismo, 18, 546-566.

Alvarado Corrales, E. (1995). El turismo en Cáceres. Cáceres: Câmara de Comércio e Indústria de Cáceres.

Amirou, R. (2007). Imaginário turístico e sociabilidades de viagem. Vila Nova de Gaia: Estratégias criativas - APTUR.

Andrade Suárez, M. J. (2012). La generación de la imagen del destino a través de las fuentes de información y comunicación turística: El caso Gallego. Revista de Estudios Regionales, 93, 17-42.

Araña, J. E., León, C. J., Carballo, M. M., e Moreno Gil, S. (2016). Design tourist information offices: The role of the human factor. Journal of Travel Research, 55(6), 764-773.

Aurindo, M. J. (2006). Portugal em cartaz. Representações do destino turístico (1911-1986). Lisboa: Centro de Estudos Geográficos da Universidade de Lisboa.

Benabente Espantoso, L. (2009). As oficinas de turismo en Galicia dende o punto de vista da oferta. Em J. A. Fraiz Brea (Coord.), O desenvolvimento turístico dende a visión dos posgraduados en dirección e planificación do turismo (pp. 8-26). Ourense: Universidade de Vigo - Xunta de Galicia.

Benckendorff, P., Zheng X., e Sheldon, P. (2019). Tourism information technology. Wallingford: CABI.

Bernardo, E. (coord.), Jorge, F., Mota, G., Bordonaro, L., Belo, M., Losada, N., Bento, R., Rodrigues, V. e Pereiro, X. (2018). Para um enfoque territorial do turismo no Douro. La Laguna (Tenerife): PASOS. Recuperado de http://www.pasosonline.org/Publicados/ pasosoedita/PSEdita21.pdf

Brito, L. M. (2013). Informação turística. Lisboa: Chiado Books.

Buhalis, D. e O'Connor, P. (2005). Information communication technology revolutionizing Tourism. Tourism Recreation Research, 30(3), 7-16. Recuperado de http://epubs.surrey. ac.uk/1130/1/fulltext.pdf

Buhalis, D., Leung, D. e Law, R. (2011). eTourism: Critical information and communication technologies for tourism destinations. Em R. Wang e A. Pizam, A., (eds), Destination marketing and management (pp. 205-224). Wallingford: CABI.

Cabo Nadal, M. (2002). Información turística en destino. Madrid: Thomson- Paraninfo. 
Cals, J., Capella, X., e Vaqué, E. (1998). Gestió del turisme. Manual per les administracions locals de les zones d'interior. Barcelona: Fundació Carles Pi I Sunyer.

Castells, M. (1997). La era de la información. Economía, sociedad y cultura. Madrid: Alianza.

Castells, Manuel (1999). La sociedad red. México: Siglo XXI.

CCDR-N (ed.) (2004). Plano de desenvolvimento turístico do Vale do Douro - Proposta técnica. Porto: CCDR-N.

CCDR-N (s.d.). Região Norte. Recuperado de https://www.ccdr-n.pt/regiao-norte/apresentacaohttps://www.ccdr-n.pt/regiao-norte/apresentacao

Claude, M. (1996). Redéfinir l'accueil dans les offices de tourisme. Cahier Espaces, 48, 158-161.

Corchero, M. (2007). Las oficinas de turismo. Pamplona: Aranzadi.

Crouch, D. y Lubbren, N. (2003). Visual culture and tourism. Oxford: Berg.

Dann, G. M.S. (1996). The language of tourism: A sociolinguistic perspective. Wallingford: CABI.

De San Eugenio Vela, J. (2012). Aproximaciones teóricas y conceptuales para una definición del estado del arte de la comunicación de los destinos turísticos. Andamios, 9(20), 211-236.

Domingues Araújo, M. I. (2015). A loja interativa na promoção turística do Porto e Norte de Portugal (tese de mestrado). Lisboa: Escola Superior de Restauração e Turismo de Estoril (relatório de estágio). Recuperado de https://comum.rcaap.pt/bitstream/10400.26/19290/1/2015.04.003 .pdf

Fernández Arderius, I. (1999). Los profesionales de la información turística. Madrid: Escuela Oficial de Turismo.

Fernandes, G., Roque, V. e Martins, J. (2013). A valorização e promoção do destino turístico e o papel dos postos de turismo. Abordagem ao destino turístico da Serra da Estrela. Em T. Correia, V. Henriques e R. Julião (Eds). Atas do IX Congresso da Geografia Portuguesa - Geografia: Espaço, Natureza, Sociedade e Ciência (pp. 184-190). Évora: APG.

Fyall, A., Callod, C. e Edwards, B. (2003). Relationship marketing: The challenge for destinations. Annals of Tourism Research, 30(3), 644-659. DOI: 10.1016/S0160-7383(03)00046-X.

Galí, J. M. (2000). Evolución de la informatización de las oficinas de turismo de Cataluña, Estudios Turísticos, 146, 83-94.

GEPE - Gabinete de Estatística e Planeamento da Educação (2011). Projecção do Parque Escolar por NUT III a 2013 - Sub-região Douro. Coimbra: Faculdade de Letras da Universidade de Coimbra.

Gomis, J. M. (2009). La informació turistica: Del paper a la xarxa. Em J. de San Eugenio Vela (coord.), Manual de comunicado turistica: de la informado a la persuasió, de la promodó a l'emodó (pp. 19-28). Girona: Documenta Universitaria.

Gonçalves, E. e Guerra, R. (eds.) (2018). Estudo de Mercado. Estratégia de marketing turístico de internacionalização. Vale do Douro. Maia: ISMAI.

Goval, B. (1996). L'accueil dans un office de tourisme. Une mission à accomplir et à faire partager. Cahier Espaces, 48, 162-163.

Hetherington, A. (1991). Rural tourism: Marketing small communities. Bainbridge Island: Meta-Link.

Izard, O. (2007). Gestión de oficinas de turismo. Barcelona: Editorial UOC.

Jiménez, M., Allés, M. T. e Franco, J. (2018). Revisión teórica de la relevancia de las nuevas tecnologías de la comunicación (TIC) en el sector turístico. Revista Turydes: Turismo y 
Desarrollo, 11(24), 1-21. Recuperado de https://www.eumed.net/rev/turydes/24/tecnologia-turismo.html

Kozinets, R. (2010). Netnography: doing ethnographic research online. Londres: Sage.

Martins Pereira, G. (2021). Território(s) Douro. Em O. Sacramento, E. Gonçalves e X. Pereiro (eds.) (2019). Douro turístico: Indagações multidisciplinares. Maia: ISMAI-CEDTURCETRAD - PASOS (em processo de publicação).

Miralbell, O. (2007). Gestión de oficinas de turismo. Barcelona: Editorial UOC.

Mota, G. e Losada, N. (2017). Promoção turística nos websites municipais: O caso da região do Douro (NUT III). Revista Portuguesa de Estudos Regionais, 47, 49-71.

Nolan, S. D. (1976). Tourists' use and evaluation of travel information sources: Summary and conclusions. Journal of Travel Research, 14(3), 6-8.

OMT (ed.) (1999). Guía para administraciones locales: Desarrollo turístico sostenible. Madrid: OMT.

Panells Costa, M. e Crespi Vallbona, M. (2002). Información turística en destino. Madrid: Síntesis.

Pereiro, X. e Fernandes. F. (2018). Antropologia e turismo. Teorias, métodos, praxis. La Laguna (Tenerife): PASOS. Recuperado de http://www.pasosonline.org/en/collections/ pasos-edits/151-numero-20-antropologia-e-turismo

Pereiro, X. e Sousa, N. A procura dos postos de turismo do Douro. In O. Sacramento, E. Gonçalves e X. Pereiro (eds.) (2021). Douro turístico: Indagações multidisciplinares. Maia: ISMAICEDTUR-CETRAD - PASOS (em processo de publicação).

Phillips, W., Wolfe, K., Hodur, N. e Leistritz, F. L. (2013). Tourist word of mouth and revisit intentions to rural tourism destinations: A case of North Dakota, USA. International Journal of Tourism Research, 15, 93-104. DOI: 10.1002/jtr.879

Picard, D. e Di Giovine, M. A. (eds.) (2014). Tourism and the power of otherness. Seductions of Difference. Bristol: Channel View.

Platon, N. (2017). The importance of tourism information and promotion office and centres in the development of inbound tourism. Economica, 1 (99), 37-51.

Poon, A. (1993). Tourism, technology and competitive strategies. Wallingford: CABI.

Pordata (2017). Dados estatísticos. Retirado de https://www.pordata.pt/DB/Municipios/ Ambiente+de+Consulta/Tabela)

Prayag, G. e Ryan, C. (2012). Antecedents of tourists' loyalty to Mauritius: The role and influence of destination image, place attachment, personal involvement, and satisfaction. Journal of Travel Research, 51(3), 342-356. DOI: 10.1177/004728751141 0321.

RNT (2019). Empreendimentos turísticos. Recuperado de https://rnt.turismodeportugal.pt/

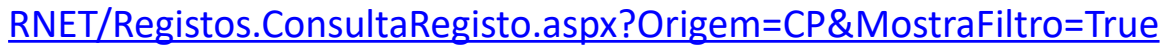

Roque, V., Poeta Fernandes, G., Sardo, A., Martins, J. A., Melo, A. (2013). Tourism promotion and the (re)functionalization of information offices. The case of Serra da Estrela. Papers de Turisme, 54, 70-87.

Salazar, N. B. e Graburn, N. H. (eds.) (2014). Tourism imaginaries: Anthropological Approaches. Oxford: Berghahn.

Sánchez Vázquez, N. (2016). O papel das oficinas de turismo na xestión do destino: Rede de oficinas de turismo de Galicia. Santiago de Compostela: Universidade de Santiago de 
Compostela (tese de doutoramento inédita). Recuperada de https://minerva.usc.es/ xmlui/handle/10347/15155

Santana, O. (2017). História do turismo no Douro. Em X. Pereiro (coord.), III Ciclo de Seminários Dourotur, UTAD: Vila Real, 19-04-2017 (inédito).

Schmidt-Rauch, S., Fux, M. e Schwabe, G. (2011). Tourist office counselling service. Em R. Law, M. Fuchs e F. Ricci (eds.), Information and communication technologies in tourism 2011 (pp. 391-402). Viena: Springer.

Selwyn, T. (1990). Tourist brochures as post-modern myths. Problemy Turystyki, 8, 13-26.

Selwyn, T. (1993). Peter Pan in South-East Asia: Views from the brochures. Em M. Hitchcock, V. King e M.J.G. Parnwell (eds.), Tourism in South-East Asia (pp. 117-137). London: Routledge.

Selwyn, T. (ed.) (1996). The tourist image: Myths and myth making in tourism. London: John Wiley and Sons.

Swanson, S. e Hsu, M. (2009). Critical incidents in tourism: Failure, recovery, customer switching, and word-of-mouth behaviors. Journal of Travel \& Tourism Marketing, 26(2), pp. 180-194. DOI: 10.1080/10548400902864800. 